九州大学学術情報リポジトリ

Kyushu University Institutional Repository

\title{
Basic Growth Analysis and Symmetric Properties of Exponential Function with Base e
}

\author{
Shimojo, Masataka \\ Laboratory of Animal Feed Science, Division of Animal Science, Department of Animal and Marine \\ Bioresource Scineces, Faculty of Agriculture, Kyushu University
}

Asano, Yoki

Laboratory of Animal Feed Science, Division of Animal Science, Department of Animal and Marine Bioresource Scineces, Graduate School of Bioresource and Bioenvironmental Sciences, Kyushu University

\section{Ikeda, Kentaro}

Laboratory of Animal Feed Science, Division of Animal Science, Department of Animal and Marine Bioresource Scineces, Graduate School of Bioresource and Bioenvironmental Sciences, Kyushu University

Ishikawa, Reiko

Research Fellow of the Japan Society for the Promotion of Science

他

https://doi.org/10.5109/24459

出版情報: 九州大学大学院農学研究院紀要. 47 (1)，pp.55-60，2002-10-30. Kyushu University バージョン：

権利関係 : 


\title{
Basic Growth Analysis and Symmetric Properties of Exponential Function with Base $e$
}

\author{
Masataka SHIMOJO*, Yoki ASANO ${ }^{1)}$, Kentaro IKEDA ${ }^{1)}$, Reiko ISHIWAKA ${ }^{2}$, \\ Tao SHAO ${ }^{3)}$, Hiroyuki SATO ${ }^{1)}$, Yukiko MATSUFUJI ${ }^{1}$, Noriko OHBA ${ }^{4}$, \\ Manabu TOBISA, Yasukatsu YANO ${ }^{5)}$ and Yasuhisa MASUDA
}

\author{
Laboratory of Animal Feed Science, Division of Animal Science, Department of \\ Animal and Marine Bioresource Sciences, Faculty of Agriculture, \\ Kyushu University, Fukuoka 812-8581, Japan \\ (Received June 28, 2002 and accepted July 12, 2002)
}

\begin{abstract}
This study of basic growth analysis suggests that the analytic description of agricultural phenomenon of growth is related to the mathematical phenomenon of symmetry on the exponential function with base $e$.
\end{abstract}

\section{INTRODUCTION}

The basic growth analysis was born in English studies of plant production in the 1910 s, as shown in many scientific publications, for example the review by Watson (1952), the paper by Radford (1967) and the book by Hunt (1990). This method was also applied to the growth analysis of farm animals (Brody, 1945). Methods for analyzing growth have been developed from the basic one into those using devised functions or mathematical modeling in order to predict growth curves more precisely by introducing factors affecting growth (for example, Milthorpe and Moorby, 1979; Parks, 1982; France and Thornley, 1984). This is one of the reasons why the basic growth analysis has not been used so frequently of late. However, without knowing why, this method, due to its simple beauty, still attracts some people who are engaged in agricultural sciences.

The present study was designed to investigate some aspects of basic growth analysis in relation to symmetric properties of the exponential function with base $e$.

\section{BASIC GROWTH ANALYSIS}

\section{Basic growth function formed using the exponential function with base $e$}

In basic growth analysis, absolute growth rate (AGR) and relative growth rate (RGR) are considered basic tools. RGR is, however, considered preferable to AGR when compar-

\footnotetext{
1) Laboratory of Animal Feed Science, Division of Animal Science, Department of Animal and Marine Bioresource Sciences, Graduate School of Bioresource and Bioenvironmental Sciences, Kyushu University

2) Research Fellow of the Japan Society for the Promotion of Science

3) Visiting Research Scientist from the People's Republic of China

4) Research Student, School of Agriculture, Kyushu University

5) Technical Specialist, School of Agriculture, Kyushu University

* Corresponding Author (E-mail: mshimojo@agr.kyushu-u.ac.jp)
} 
isons are made between weights that are different each other. Our previous reports also showed that RGR played an important role when ruminant growth analysis and forage growth analysis were related (Shimojo et al., 1998a, b, 1999a, b, 2000).

RGR is given by

$$
\mathrm{RGR}=\frac{1}{W} \cdot \frac{d W}{d t}
$$

where $W=$ weight, $t=$ time, RGR is some constant.

The basic growth function is derived from equation (1) according to the following procedure:

$$
\begin{aligned}
& \int(\mathrm{RGR}) d t=\int \frac{d W}{W}, \\
& (\mathrm{RGR}) \cdot t+C_{1}=\log _{e} W+C_{2}, \\
& \log _{e} W=C+(\mathrm{RGR}) \cdot t, \\
& W=(\exp C) \cdot \exp (\mathrm{RGR}) \cdot t\},
\end{aligned}
$$

where $C\left(=C_{1}-C_{2}\right)$ is the constant of integration.

When $W=W_{0}$ at $t=0$ in equation (2), $\exp C=W_{0}$ because $\exp \{(\mathrm{RGR}) \cdot 0\}=1$. In case of $C=0$ $\left(C_{1}=C_{2}\right), W_{0}=\exp (0)=1$ and $W$ will show relative values when $W_{0}=1$. Therefore, $C \neq 0\left(C_{1}\right.$ $\neq C_{2}$ ) is required in order that $W_{0}$ and $W$ take values of actual weight. This is considered an agricultural significance of integration constant on the basic growth function. Thus,

$$
W=W_{0} \cdot \exp \{(\mathrm{RGR}) \cdot t\}
$$

where $W_{0}$ is the value at $t=0$.

Equation (3) has a form of multiplication. Transforming this into a form of addition using natural logarithms is given by

$$
\begin{aligned}
\log _{e} W & =\log _{e}\left[W_{0} \cdot \exp \{(\mathrm{RGR}) \cdot t\}\right] \\
& =\log _{e} W_{0}+(\mathrm{RGR}) \cdot t,
\end{aligned}
$$

therefore,

$$
\frac{\log _{e} W-\log _{e} W_{0}}{t}=\text { RGR. }
$$

This is considered the original of the following equation (5) that is used for calculating mean RGR over a certain period of time (from $t_{1}$ to $t_{2}$ ),

$$
\frac{\log _{e} W_{2}-\log _{e} W_{1}}{t_{2}-t_{1}}=\text { mean RGR. }
$$

\section{AGR}

AGR is given by differentiating equation (3) with respect to $t$. Thus, 


$$
\begin{aligned}
\mathrm{AGR} & =\frac{d}{d t}(W) \\
& =\frac{d}{d t}\left[W_{0} \cdot \exp \{(\mathrm{RGR}) \cdot t\}\right] \\
& =(\mathrm{RGR}) \cdot W_{0} \cdot \exp \{(\mathrm{RGR}) \cdot t\} .
\end{aligned}
$$

Differentiating $\exp \{(\mathrm{RGR}) \cdot t\}$ with respect to $t$ gives $(\mathrm{RGR}) \cdot \exp \{(\mathrm{RGR}) \cdot t\}$, where the form of $\exp \{(\mathrm{RGR}) \cdot t\}$ itself has not been changed.

\section{Increase in weight}

The increase in weight from $W_{0}$ to $W$ is given by the definite integral of AGR from 0 to t. Thus,

$$
\begin{aligned}
W-W_{0} & =\int_{0}^{t}(\mathrm{AGR}) d t \\
& =\int_{0}^{t}\left[(\mathrm{RGR}) \cdot W_{0} \cdot \exp \{(\mathrm{RGR}) \cdot t\}\right] d t \\
& =W_{0} \cdot(\mathrm{RGR}) \cdot \frac{[\exp \{(\mathrm{RGR}) \cdot t\}]_{0}^{t}}{\mathrm{RGR}} \\
& =W_{0} \cdot \exp \{(\mathrm{RGR}) \cdot t\}-W_{0} .
\end{aligned}
$$

The integral of $\exp \{(\mathrm{RGR}) \cdot t\}$ gives the primitive function, $\exp \{(\mathrm{RGR}) \cdot t\} /(\mathrm{RGR})$, without changes in the form of $\exp \{(\mathrm{RGR}) \cdot t\}$ itself.

\section{Maclaurin's series of $\exp [(\mathrm{RGR}) \cdot t]$}

The use of Maclaurin's series (infinite power series) might be expected to show how the form of $\exp \{(\mathrm{RGR}) \cdot t\}$ itself is kept invariant when differentiated or integrated with respect to $t$. Maclaurin's series of $\exp \{(\mathrm{RGR}) \cdot t\}$ is given by

$$
\begin{aligned}
\exp \{(\mathrm{RGR}) \cdot t\} & =1+\sum_{n=1}^{\infty} \frac{\{(\mathrm{RGR}) \cdot t\}^{n}}{n !} \\
& =1+\frac{(\mathrm{RGR}) \cdot t}{1 !}+\frac{(\mathrm{RGR})^{2} \cdot t^{2}}{2 !}+\cdots \cdots+\frac{(\mathrm{RGR})^{n} \cdot t^{n}}{n !}+\cdots \cdots
\end{aligned}
$$

Like $\exp \{(\mathrm{RGR}) \cdot t\}$, its Maclaurin's series is kept invariant when differentiated or integrated with respect to $t$, and in addition it shows invariance with respect to the interchange between RGR and $t$.

\section{Deriving AGR by differentiating Maclaurin's series of exp $($ RGR) $\cdot t$ \}}

Using (8) the following differentiation is taken up,

$$
\begin{aligned}
P & =\frac{d}{d t}\left[W_{0} \cdot \exp ((\mathrm{RGR}) \cdot t\}\right] \\
& =\frac{d}{d t}\left[W_{0} \cdot\left\{1+\frac{(\mathrm{RGR}) \cdot t}{1 !}+\frac{(\mathrm{RGR})^{2} \cdot t^{2}}{2 !}+\cdots \cdots+\frac{(\mathrm{RGR})^{n} \cdot t^{n}}{n !}+\cdots \cdots \cdot\right]\right] \\
& =W_{0} \cdot\left\{\mathrm{RGR}+\frac{(\mathrm{RGR})^{2} \cdot t}{1 !}+\frac{(\mathrm{RGR})^{3} \cdot t^{2}}{2 !}+\cdots \cdots+\frac{(\mathrm{RGR})^{n+1} \cdot t^{n}}{n !}+\cdots \cdots\right\} .
\end{aligned}
$$


There are two discrepancies when infinite power series in the braces of equation (9) is compared with Maclaurin's series of $\exp (\mathrm{RGR}) \cdot t$; the exponent of RGR is greater than that of $t$ by one and there is a disappearance of 1 . These two discrepancies must be corrected. In order to recover Maclaruin's series of $\exp \{(\mathrm{RGR}) \cdot t\}$, an extra RGR in each term is required to move to the outside of the braces. Thus,

$$
\begin{aligned}
P & =(\mathrm{RGR}) \cdot W_{0} \cdot\left\{1+\frac{(\mathrm{RGR}) \cdot t}{1 !}+\frac{(\mathrm{RGR})^{2} \cdot t^{2}}{2 !}+\cdots \cdots+\frac{(\mathrm{RGR})^{n} \cdot t^{n}}{n !}+\cdots \cdots\right\} \\
& =(\mathrm{RGR}) \cdot W_{0} \cdot \exp ((\mathrm{RGR}) \cdot t\} \\
& =\mathrm{AGR} .
\end{aligned}
$$

This shows that AGR results from the event that is required to occur in order to keep the form of $\exp \{(\mathrm{RGR}) \cdot t\}$ itself invariant when $W$ is differentiated with respect to $t$. In brief, AGR is related to symmetric properties of $\exp \{(\mathrm{RGR}) \cdot t\}$ with respect to its differentiation.

\section{Deriving the increase in weight by the definite integral of Maclaurin's series of $\exp \{(\mathrm{RGR}) \cdot t\}$ from 0 to $t$}

Using (8) the following integration is taken up,

$$
\begin{aligned}
Q & =\int_{0}^{t}\left[(\mathrm{RGR}) \cdot W_{0} \cdot \exp \{(\mathrm{RGR}) \cdot t\}\right] d t \\
& =(\mathrm{RGR}) \cdot W_{0} \cdot \int_{0}^{t}\left\{1+\frac{(\mathrm{RGR}) \cdot t}{1 !}+\frac{(\mathrm{RGR})^{2} \cdot t^{2}}{2 !}+\cdots \cdots+\frac{(\mathrm{RGR})^{n} \cdot t^{n}}{n !}+\cdots \cdots\right\} d t \\
& =(\mathrm{RGR}) \cdot W_{0} \cdot\left[\frac{t}{1 !}+\frac{(\mathrm{RGR}) \cdot t^{2}}{2 !}+\cdots \cdots+\frac{(\mathrm{RGR})^{n-1} \cdot t^{n}}{n !}+\left.\cdots \cdots\right|_{0} ^{t} .\right.
\end{aligned}
$$

Two discrepancies have occurred when infinite power series in the square brackets of equation (11) is compared with Maclaurin's series of $\exp \{(\mathrm{RGR}) \cdot t\}$; the exponent of RGR is less than that of $t$ by one and there is a disappearance of 1 . These two discrepancies must be corrected. In order to recover Maclaruin's series of $\exp \{(\mathrm{RGR}) \cdot t\}$, the following two events are required to occur. (i) An RGR is required to get back into the square brackets from the outside. (ii) 1 is required to appear according to the equality, $0=1+(-1)$, a pair appearance of 1 and -1 from 0 . Thus,

$$
\begin{aligned}
Q & =W_{0} \cdot\left[\left\{1+\frac{(\mathrm{RGR}) \cdot t}{1 !}+\frac{(\mathrm{RGR})^{2} \cdot t^{2}}{2 !}+\cdots \cdots+\frac{(\mathrm{RGR})^{n} \cdot t^{n}}{n !}+\cdots \cdots \cdot-1\right]_{0}^{t}\right. \\
& =W_{0} \cdot[\exp \{(\mathrm{RGR}) \cdot t\}-1]_{0}^{t} .
\end{aligned}
$$

If -1 is regarded as one of the integration constants for $\exp \{(\mathrm{RGR}) \cdot t\}$, then

$$
\begin{aligned}
Q & =W_{0} \cdot[\{\exp \{(\mathrm{RGR}) \cdot t\}-1\}-\{\exp \{(\mathrm{RGR}) \cdot 0\}-1\}] \\
& =W_{0} \cdot[\exp \{(\mathrm{RGR}) \cdot t\}-\exp \{(\mathrm{RGR}) \cdot 0\}] \\
& =W_{0} \cdot[\exp \{(\mathrm{RGR}) \cdot t\}-1] \\
& =W-W_{0}
\end{aligned}
$$


where -1 has disappeared, the property of integration constants that do not affect at all the calculation of definite integrals.

Equations (11) (13) show that after the pair appearance of 1 and -1 from 0,1 has been taken in, together with an RGR, by infinite power series of (11) in order to get back to $\exp \{(\mathrm{RGR}) \cdot t\}$, but, in contrast, -1 has disappeared on the way to (13). This suggests a case, where the pair appearance of 1 and -1 from 0 , the remaining of 1 and the disappearing of -1 are a series of events related to symmetric properties of $\exp \{(\mathrm{RGR}) \cdot t\}$ with respect to its definite integral from 0 to $t$. These show that the increase in weight results from the events that are required to occur in order to keep the form of $\exp \{(\mathrm{RGR}) \cdot t\}$ itself invariant on the definite integral of AGR from 0 to $t$. In brief, the increase in weight is related to symmetric properties of $\exp \{(\mathrm{RGR}) \cdot t\}$ with respect to its definite integral from 0 to $t$.

\section{$W, A G R$ and growth acceleration}

The exponential function with base $e$ is infinitely differentiable, and the existence of the second derivative causes the change in AGR, which is tentatively called growth acceleration. Thus,

$$
\text { Growth acceleration }=\frac{d}{d t}(\mathrm{AGR})=\frac{d^{2} W}{d t^{2}}=(\mathrm{RGR})^{2} \cdot W_{0} \cdot \exp \{(\mathrm{RGR}) \cdot t\} .
$$

From equations (3), (6) and (14) the relationship among $W$, AGR and growth acceleration is given by

$$
\frac{\mathrm{AGR}}{W}=\frac{\text { Growth acceleration }}{\mathrm{AGR}}=\mathrm{RGR},
$$

where it is shown that RGR connects $W$, AGR and growth acceleration.

Then, this gives

$$
W \cdot(\text { Growth acceleration })=(\text { AGR })^{2},
$$

showing that each term is described using the other two. Thus,

$$
\begin{aligned}
& W=\frac{(\mathrm{AGR})^{2}}{\text { Growth acceleration }}, \\
& \text { Growth acceleration }=\frac{(\mathrm{AGR})^{2}}{W} .
\end{aligned}
$$

Relationships (15) $\sim(18)$ result from symmetric properties of $\exp \{(\mathrm{RGR}) \cdot t\}$ itself with respect to its differentiation, where $W\left[=W_{0} \cdot \exp \{(\mathrm{RGR}) \cdot t\}\right]$ is included in both AGR and growth acceleration.

Since AGR takes the form of $(A G R)^{2}$ in $(16) \sim(18)$, there is a possibility that AGR takes not only positive values but also negative values, the decrease in weight when AGR $<0$. The negative AGR (-AGR) causes the negative RGR $(-R G R)$. If this is described using the method of basic growth analysis, then

$$
-\mathrm{AGR}=(-\mathrm{RGR}) \cdot W_{0} \cdot \exp \{(-\mathrm{RGR}) \cdot t\}
$$

where $W_{0} \cdot \exp \{(-\mathrm{RGR}) \cdot t\}<W_{0}$.

The replacements $(-\mathrm{RGR} \rightarrow \mathrm{RGR}, t \rightarrow-t)$ in $W_{0} \cdot \exp \{(-\mathrm{RGR}) \cdot t$ ) do not change its value, 
because both equations are equal to $W_{0} \cdot \exp [-\{(\mathrm{RGR}) \cdot t\}]$. Thus,

$$
W_{0} \cdot \exp \{(-\mathrm{RGR}) \cdot t\}=W_{0} \cdot \exp \{(\mathrm{RGR}) \cdot(-t)\} \text {. }
$$

The relation (20) suggests that the negative RGR moving forward in time (left-hand side) might look like the positive RGR moving backward in time (right-hand side), provided that the attention is given to the decrease in weight and physiological aging is not considered. This may be regarded as the waste of time in such agricultural production as people pursue its efficiency only. It is also suggested that a kind of agricultural significance is given to the reverse direction of time resulting from symmetric properties of the exponential function with base $e$.

\section{CONCLUSIONS}

It is concluded in basic growth analysis that AGR and the increase in weight are derived from the events that are required to occur in order to keep the form of $\exp \{(\mathrm{RGR}) \cdot t\}$ itself invariant when differentiated and integrated with respect to $t$. This suggests that the analytic description of agricultural phenomenon of growth is related to the mathematical phenomenon of symmetry on the exponential function with base $e$.

\section{REFERENCES}

Brody, S. 1945 Time relations of growth of individuals and populations. In "Bioenergetics and growth", Reinhold Publishing Corporation, New York, pp. 484-574

France, J. and J. H. M. Thornley 1984 Growth functions. In "Mathematical Models in Agriculture - A Quantitative Approach to Problems in Agriculture and Related Sciences", Butterworth \& Co (Publishers) Ltd, London, pp. 75-94

Hunt, R. 1990 Basic Growth Analysis. Unwin Hyman Ltd., London.

Milthorpe, F. L. and J. Moorby 1979 Some commonly used functions. In "An introduction to crop physiology", Cambridge University Press, Cambridge, pp. 224-227

Parks, J. R. 1982 A theory of feeding and growth of animals. Springer-Verlag, New York.

Radford, P.J. 1967 Growth analysis formulae-their use and abuse. Crop Sci, 7: 171-175

Shimojo, M., T. Bungo, M. Tobisa, Y. Imura, N. Koga, S. Tao, M. Yunus, Y. Nakano, I. Goto, M. Furuse and Y. Masuda 1998a A hypothetic equation from which growth analysis equations of forages and ruminants are derived as special cases. J. Fac. Agr., Kyushu Univ., 43: 103-109

Shimojo, M., T. Bungo, N. Koga, Y. Imura, M. Tobisa, S. Tao, M. Yunus, Y. Nakano, I. Goto, M. Furuse and Y. Masuda 1998b An equation with a potential for describing relative growth rate of forages and of ruminants using related component factors. Proc. 8 th World Conf. Anim. Prod., Seoul, Korea, Vol. II: $510-511$

Shimojo, M., T. Bungo, Y. Imura, M. Tobisa, N. Koga, T. Shao, M. Yunus, Y. Nakano, I. Goto, M. Furuse and Y. Masuda 1999a Two different-type equations of relative growth analysis for both forages and ruminants and deriving of them from a hypothetic equation. J. Fac. Agr., Kyushu Univ., 43: 355-364

Shimojo, M., T. Bungo, M. Tobisa, Y. Imura, N. Koga, T. Shao, M. Yunus, Y. Nakano, I. Goto, M. Furuse and Y. Masuda 1999b Net assimilation rate of forages and forage intake of ruminants as related using a hypothetic equation suggested to growth analysis of both forages and ruminants. J. Fac. Agr., Kyushu Univ., 43: 365-371

Shimojo, M., T. Bungo, Y. Imura, M. Tobisa, M. Furuse, Y. Masuda, Y. Yano, Y. Nakano, T. Shao, M. Yunus and I. Goto 2000 Contrastive or interconvertible relationships between forage and ruminant growth analysis equations -A simple description using a symmetry-like characteristic-. J. Fac. Agr., Kyushu Univ., 44: 279-285

Watson, D. J. 1952 The physiological basis of variation in yield. Adv. Agron., 4: 101-145 